Article

\title{
Design of Morphology-Controllable ZnO Nanorods/Nanopariticles Composite for Enhanced Performance of Dye-Sensitized Solar Cells
}

\author{
Dongting Wang ${ }^{1, *}$, Yuting Zhang ${ }^{1}$, Meng Su ${ }^{1}$, Ting Xu ${ }^{1}$, Haizhou Yang ${ }^{1}$, Shiqing Bi ${ }^{2}$, \\ Xianxi Zhang ${ }^{1}$, Yuzhen Fang ${ }^{1}$ and Jinsheng Zhao ${ }^{1}$ \\ 1 School of Chemistry and Chemical Engineering, Shandong Provincial Key Laboratory, Liaocheng University, \\ Liaocheng 252059, Shandong Province, China \\ 2 School of Chemistry and Chemical Engineering, Yulin University, Yulin 719000, Shaanxi Province, China \\ * Correspondence: wangdongting@lcu.edu.cn; Tel.: +86-635-8230680; Fax: +86-635-8239001
}

Received: 22 May 2019; Accepted: 17 June 2019; Published: 28 June 2019

\begin{abstract}
A facile one-pot approach was developed for the synthesis of $\mathrm{ZnO}$ nanorods (NRs)/nanoparticles (NPs) architectures with controllable morphologies. The concrete state of existence of NPs and NRs could rationally be controlled through reaction temperature manipulation, i.e., reactions occured at $120,140,160$, and $180^{\circ} \mathrm{C}$ without stirring resulted in orderly aligned NRs, disordered but connected NRs/NPs, and relatively dispersed NRs/NPs with different sizes and lengths, respectively. The as-obained $\mathrm{ZnO}$ nanostructures were then applied to construct photoanodes of dye-sensitized solar cells, and the thicknesses of the resultant films were controlled for performance optimization. Under an optimized condition (i.e., with a film thickness of $14.7 \mu \mathrm{m}$ ), the device fabricated with the material synthesized at $160{ }^{\circ} \mathrm{C}$ exhibited the highest conversion efficiency of $4.30 \%$ with an elevated current density of $14.50 \mathrm{~mA} \cdot \mathrm{cm}^{-2}$ and an open circuit voltage of $0.567 \mathrm{~V}$. The enhanced performance could be attributed to the coordination effects of the significantly enhanced dye absorption capability arising from the introduced NPs and the intrinsic fast electron transport property of NRs as confirmed by electrochemical impedance spectroscopy (EIS) and ultraviolet-visible (UV-vis) absorption.
\end{abstract}

Keywords: ZnO; nanorods/nanopariticles; morphology control; dye sensitized solar cells

\section{Introduction}

Dye-sensitized solar cells (DSCs) constructed from nanostructured metal oxides such as photoanode materials are potential alternatives to conventional silicon-based photovoltaics due to their benefits of low cost, long-term stability, environmental compatibility, and ease of fabrication [1-5]. Since their introduction by Grätzel., great efforts have been devoted to the improvement of powder conversion efficiency (PCE) of $\mathrm{TiO}_{2}$-based DSCs [6]. So far, impressive efficiency reaching up to $13 \%$ has been recorded with porphyrin-based $\mathrm{D}-\mathrm{p}-\mathrm{A}$ dye used in conjunction with cobalt-based redox couple [7]. However, a major drawback of the traditional $\mathrm{TiO}_{2}$ nanoparticle (NP) photoanode in DSCs is the intrinsic charge recombination rate arising from sluggish electron mobility and transport properties, thus imposing an upper limit on the state-of-the-art film thickness. Underlying the background, many other oxide semiconductors with high electron transport properties have been considered and found to be promising. For instance, $\mathrm{ZnO}, \mathrm{Zn}_{2} \mathrm{SnO}_{4}, \mathrm{SnO}_{2}$ and $\mathrm{Nb}_{2} \mathrm{O}_{5}$ have already been demonstrated as applicable materials for photoanodes [8-12]. In particular, $\mathrm{ZnO}$ has attracted widespread attention due to many remarkable advantages, such as suitable energy band position for effective electron-injection from the sensitizer and higher electron mobility $\left(205-1000 \mathrm{~cm}^{2} \cdot \mathrm{V}^{-1} \cdot \mathrm{s}^{-1}\right)$ in 
comparison with $\mathrm{TiO}_{2}\left(0.1-4 \mathrm{~cm}^{2} \cdot \mathrm{V}^{-1} \cdot \mathrm{s}^{-1}\right)$ that enables faster electron transport within the photoanode film. In addition, the ease of the anisotropic growth property makes it possible to acquire specific structures with desirable features [13-15]. So far, an unprecedented efficiency up to 7.5\% has been reported for $\mathrm{ZnO}$-based DSCs with the photoelectrode film composed of a buffer layer and multifunctional polydispersed aggregates [16]. However, the validated efficiencies of the DSC devices based on $\mathrm{ZnO}$ were only approximately two-fold below those based on $\mathrm{TiO}_{2}$, leaving plenty of operational space for improvement of the PCE through morphological and structural modifications.

Constructing well-organized nanostructures, especially one-dimensional (1-D) structures, such as nanotubes arrays, [17] nanorods (NRs), [18] and nanowires (NWs) [19] is deemed an effective route to reduce the severe charge recombination due to direct high electron transfer pathway along the peculiar nanostructures. For instance, Galoppini et al. compared the electron transport properties of the photoanodes based on ZnO NRs array and colloids, and noticed that electron transport in the device with ZnO NRs photoanode was approximately 2-fold faster than that in $\mathrm{ZnO}$ colloids [20]. Besides, Kretzschmar et al. observed that the electron lifetime in photoanode films fabricated with NRs was 2 times longer compared to that with nanoparticles [21]. Apart from efficient electron transport, 1-D nanostructures with tunable lengths ranging from hundreds of nanometers to micrometers are also promising light-scattering centers with enhanced optical propagation distance within the films and improved light collection efficiencies [22-24]. Nevertheless, excessive loss of accessible surface area and thus insufficient dye loading of these $\mathrm{ZnO}$ nanostructures limits their attainable photovoltaic efficiency to a relatively low level, making them less competitive in current DSCs embodiments.

Construction of the hybrid photoanode films with different nanostructures turns out to be promising for balancing the device electrical conductivity with the dye adsorption capability. Following this strategy, 1-D/0-D composite photoanodes have been designed via various methods to combine the desirable advantages of each component [25-27]. For example, Xiong et al. constructed ZnO composites for photoanode applications by blending the as-prepared electrospun $\mathrm{ZnO} \mathrm{NWs}$ with $\mathrm{ZnO}$ NPs. The obtained hybrid film delivered a high conversion efficiency of $2.6 \%$, which was almost 2 -fold higher than that of cells constructed with single $\mathrm{ZnO}$ nanostructure [28]. Cao et al. designed $\mathrm{ZnO}$ NPs-NWs array hybrid photoanodes by spin-coating of colloidal dispersion of ZnO NPs on top of the prepared ZnO NW arrays perpendicularly grown on fluorine-doped tin oxide (FTO) substrate, within which NPs play the role of offering a large overall surface area for sufficient dye adsorption and NW arrays act as a direct pathway for fast electron transport. Consequently, an overall PCE of $4.2 \%$ was obtained for the NWs-NPs composite photoanode, remarkably higher than that of ZnO NWs DSC ( 1.58\%), suggesting the great contribution of ZnO NPs to the photovoltaic performance [29]. The aforementioned investigations all demonstrated the feasibility of significantly improving the conversion efficiencies of 1-D nanostructures by introducing 0-D NPs. Nevertheless, the current reports mainly focused on vertically aligned $\mathrm{ZnO}$ nanorod and nanowire arrays, and less attention was paid to other 1-D nanostructures. On the other hand, the synthesis of the composite layer generally involves a multistep process, i.e., first formation of $\mathrm{ZnO}$ seeds layer on the substrate, followed by the growth of $\mathrm{ZnO}$ NWs array on $\mathrm{ZnO}$ seeding/substrates through hydrothermal methods, and eventually followed by introducing ZnO NPs between these NWs which, however, not only increases the instruments cost but also restricts the possibility of delicately tuning the concrete state of NPs and/or 1-D stuctures. For these reasons, simpler and controllable synthesis methods allowing direct fabrication of $\mathrm{ZnO}$ composite nanostructures are highly desirable for DSCs applications.

Herein, we report a simple one-step solvothermal method for the preparation of innovative $\mathrm{ZnO}$ hybrid architecture composed of 1-D ZnO NRs and 0-D ZnO NPs, in which ZnO NPs could offer large surface area for dye absorption while 1-D ZnO NRs could provide direct electron transport highway and act as light-scattering centers. A key feature of the intentionally designed synthesis route is to tune synchronously the connectivity and dispersion of ZnO NPs and NRs by controlling the reaction temperature. The obtained $\mathrm{ZnO}$ materials were then used to construct photoanodes of DSCs, and the photovoltaic tests revealed that the efficiencies were strongly dependent on the reaction temperature 
and film thickness. Under an optimized condition, a maximum efficiency of $4.30 \%$ was achieved with the photoanode assembled with $14.7 \mu \mathrm{m}$-thick $\mathrm{ZnO}$ composite synthesized at $160{ }^{\circ} \mathrm{C}$. Various measurements, including ultaviolet-visible (UV-vis) absorption and electrochemical impedance spectroscopy (EIS), ascribed the optimum performance to the excellent fast electron transport combined with large surface area and strong light scattering.

\section{Experimental Section}

\subsection{Materials}

Anhydrous lithium iodide (LiI, 99.5\%), tert-butylpyridine (t-BPy, 96\%), iodide $\left(\mathrm{I}_{2}, 99 \%\right)$, 3-methoxypropionitrile (99\%), acetonitrile (99.9\%), 2,3-dimethyl-1-propyl imidazolium iodide (DMPII, $99 \%)$, and chloroplatinic acid $\left(\mathrm{H}_{2} \mathrm{PtCl}_{6}, 99.9 \%\right)$ were all received from Sigma. Diethylene glycol $\left(\left(\mathrm{HOCH}_{2} \mathrm{CH}_{2}\right)_{2} \mathrm{O}\right)$, zinc acetate dehydrate $\left(\left(\mathrm{CH}_{3} \mathrm{COO}\right)_{2} \mathrm{Zn}, 99.0 \%\right)$, and anhydrous ethanol were all used as purchased from commercial sources without further treatment. Ru-based N719 dye [cis-bis(isothiocyanato)bis-(2,2-bipyridyl-4,4-dicarboxylato) ruthenium (II) bis(tetrabutyl-ammonium)] was provided by dyesol (New South Wales, Australia).

\subsection{Preparation of $\mathrm{ZnO}$ Hybrid Nanostructures}

Various $\mathrm{ZnO}$ architectures were synthesized via a simple polyol-mediated solvothermal approach, similar to the method reported by Cao et al. [30]. For example, the synthetic procedure of $\mathrm{ZnO}$ at $160{ }^{\circ} \mathrm{C}$ was performed by adding $1.416 \mathrm{~g}$ zinc acetate dihydrate to a $100 \mathrm{~mL}$ Teflon liner containing $60 \mathrm{~mL}$ diethylene glycol, followed by transfering the mixture into a stainless steel autoclave. After heating for $8 \mathrm{~h}$ at $160{ }^{\circ} \mathrm{C}$ in an oven without stirring, the as-obtained colloidal suspension was centrifuged at $8000 \mathrm{rpm}$ for $15 \mathrm{~min}$ to deposit $\mathrm{ZnO}$ from the above solvent, followed by repeating centrifugation-dispersion with ethanol several times. The collected precipitate was finally dried at $60^{\circ} \mathrm{C}$ for $8 \mathrm{~h}$ at ambient condition and subsequently grinded for further use. In parallel, other three $\mathrm{ZnO}$ samples prepared at the temperatures of $120^{\circ} \mathrm{C}, 140{ }^{\circ} \mathrm{C}$, and $180^{\circ} \mathrm{C}$ were obtained following the same precedure as mentioned above. For simplicity, all four samples are referred to as Z1, Z2, Z3, and Z4 successively with the increasing order of temperature used for synthesis.

\subsection{Preparation of ZnO Electrodes and Dye-Sensitized Solar Cells (DSCs)}

A viscous $\mathrm{ZnO}$ paste was synthesized by mixing the as-prepared $\mathrm{ZnO}$ with ethyl cellulose and terpineol at weight ratio of 1:0.5:3, followed by continuous grinding for approximately $1 \mathrm{~h}$ [9]. Prior to fabrication of $\mathrm{ZnO}$ photoanode, the substrate, namely FTO conducting glass (Nippon Sheet Glass (NSG), $7 \Omega / s q$ ) was ultrasonically cleaned sequentially in $\mathrm{HCl}$, acetone, and ethanol for $15 \mathrm{~min}$ each. Afterwards, the obtained $\mathrm{ZnO}$ colloid was spread on FTO substrate using a typical doctor-blading method to form a photoanode film with an active area of $0.16 \mathrm{~cm}^{2}$. After being allowed to dry, the $\mathrm{ZnO}$ films were treated in programmed heating of $325^{\circ} \mathrm{C}$ for $5 \mathrm{~min}$, then $375{ }^{\circ} \mathrm{C}$ for $5 \mathrm{~min}$, stepwise to $450{ }^{\circ} \mathrm{C}$ for $15 \mathrm{~min}$, and finally $500^{\circ} \mathrm{C}$ for $15 \mathrm{~min}$ for the sake of removing the residual components and also strengthening the contact between FTO substrate and film, as well as that between $\mathrm{ZnO}$ products. The control over the $\mathrm{ZnO}$ film thickness was achieved by adjusting the layer of the adhesive tape, yielding $\mathrm{ZnO}$ photoanode films with thicknesses of 9.8, 14.7 and $20 \mu \mathrm{m}$.

The working electrodes were prepared by soaking the $\mathrm{ZnO}$ films in $0.5 \mathrm{mM}$ ethanolic solution of N719 dye for $60 \mathrm{~min}$ at room temperature followed by careful rinsing to remove unabsorbed dye from the surface. The corresponding counter electrodes were prepared by drop-casting of $\mathrm{H}_{2} \mathrm{PtCl}_{6}$ solution $(0.35 \mathrm{mM})$ on FTO substrate followed by annealing at $400{ }^{\circ} \mathrm{C}$ for $30 \mathrm{~min}$. The sensitized $\mathrm{ZnO}$ photoanode and Pt-coated photocathode were then assembled to fabricate an open sandwich cell with $60 \mu \mathrm{m}$-thick surlyn sheets as separating layer. A drop of $\mathrm{I}^{-} / \mathrm{I}_{3}{ }^{-}$-based electrolyte $\left(0.12 \mathrm{M} \mathrm{I}_{2}, 1.0 \mathrm{M}\right.$ DMPII, 0.5 M t-BPy and 0.1 M LiI in 3-methoxypropionitrile) was added from one side to fill the whole internal space between the two electrodes by vacuum backfilling. 


\subsection{Material Characterization and Photoelectrochemical Measurements}

The crystal structures of the ZnO powders were identified by X-ray diffractometer (XRD, X'Pert PRO MPD, Panalytical, Almelo, Netherlands). The morphologies were examined by field emission scanning electron microscope (FE-SEM, SU8000, Hitachi, Tokyo, Japan) and transmission electron microscopy (TEM, JEOL-2010, Hitachi, Tokyo, Japan and Talos F200 X, Thermo Fisher, Massachusetts, USA). The specific surface areas of the materials were acquired from Brunauer-Emmett-Teller (BET) $\mathrm{N}_{2}$ adsorption-desorption (Autosorb iQ-XR Analyzer, Quantachrome Instruments, Boynton Beach, FL, USA). The measurement of the dye loading amount on photoanode surfaces was performed by fully desorbing the anchored dye from sensitized $\mathrm{ZnO}$ films into mixed solution of water and ethanol (50:50, $v / v$ ) containing 1.0 M NaOH, following the quantitative analysis with UV-vis spectrophotometry (Cary 500, Varian, Palo Alto, CA, USA). The incident photon-to-current conversion efficiency (IPCE) values and reflectance properties of the samples were investigated by a PV measurements QEX10 instrument with the wavelength range of 200-800 $\mathrm{nm}$. The performances of assembled solar cells were evaluated by a photocurrent-voltage (J-V) analysis instrument (PV Measurements, IV5, Newport Corporation, Los Angeles, CA, USA) coupled with a class solar simulator. Prior to specimen measurement, calibration of the solar-simulated light intensity was conducted by means of NREL calibrated Si solar cell (PV Measurements, Inc., Boulder, CO, USA). The electrochemical impedance spectroscopy (EIS) analyses of DSCs were obtained on an electrochemical workstation (CHI760, CH Instruments, Shanghai, China). An open-circuit voltage and AC amplitude of $10 \mathrm{mV}$ were applied during EIS measurements and frequencies ranging from 0.1 to $10^{5} \mathrm{~Hz}$.

\section{Results and Discussion}

\subsection{Morphological Characterization}

Figure 1 clearly show the typical SEM images of all these $\mathrm{ZnO}$ samples, where Figure 1a-d are corresponding to the products that belong to $\mathrm{Z} 1$ through $\mathrm{Z} 4$, respectively. As shown in Figures $1 \mathrm{a}$ and $2 \mathrm{a}$, the $\mathrm{ZnO}$ sample prepared at $120^{\circ} \mathrm{C}$ (i.e., Z1) is mainly composed of a fan-shaped bundle assembled by orderly aligned NRs with lengths less than $300 \mathrm{~mm}$. It is worth noting that the morphology of the constitutional unit looks quite different, with one side of the NR displaying flat and smooth surface with a typical hexagonal edge while the other end assembled by connected NPs showing a rough surface (Figure S1a). The magnified TEM image in Figure S1b revealed distinct diameter difference in single NR, changing from $10 \mathrm{~nm}$ at the bottom to about $30 \mathrm{~nm}$ at the tip. Apart from the part involved in the fan-shaped bundle, other NPs tended to aggregate together to yield rare individual nanoparticles (Figure S1c). A further high-resolution TEM (HRTEM) image (Figure 2b) of individual NR displayed high crystallinity of the synthesized products with wurtzite hexagonal structure. Lattice fringe measurement based on the HRTEM image was also conducted, and the obtained interplanar spacing $(\mathrm{d}=0.26 \mathrm{~nm})$ was closely consistent with the adjacent $\mathrm{d}$-spacing of (001) plane of $\mathrm{ZnO}$ [31,32]. When the reaction temperature was altered to $140{ }^{\circ} \mathrm{C}$, the fanlike bundle vanished accompanied with the formation disordered NPs and NRs. As shown in Figure 1b, the lengths of the rods clearly reduced and morphology became more irregular when compared to that displayed in Figure 1 a. More importantly, TEM image in Figure 2c clearly revealed that the newly formed $\mathrm{ZnO}$ were apt to adhere with each other, implying partial retention of aggregation or interconnection of the particular structure. Such a morphological feature is believed to be favorable for fast electron transport rather than dye adsorption attributed to decreased surface area (see Table 1). The single crystalline feature of Z2 was also observed in perfectly aligned lattice fringes (Figure 2d) with estimated interplane spacing around $0.26 \mathrm{~nm}$, matching well with the (001) plane of wurtzite $\mathrm{ZnO}$. 


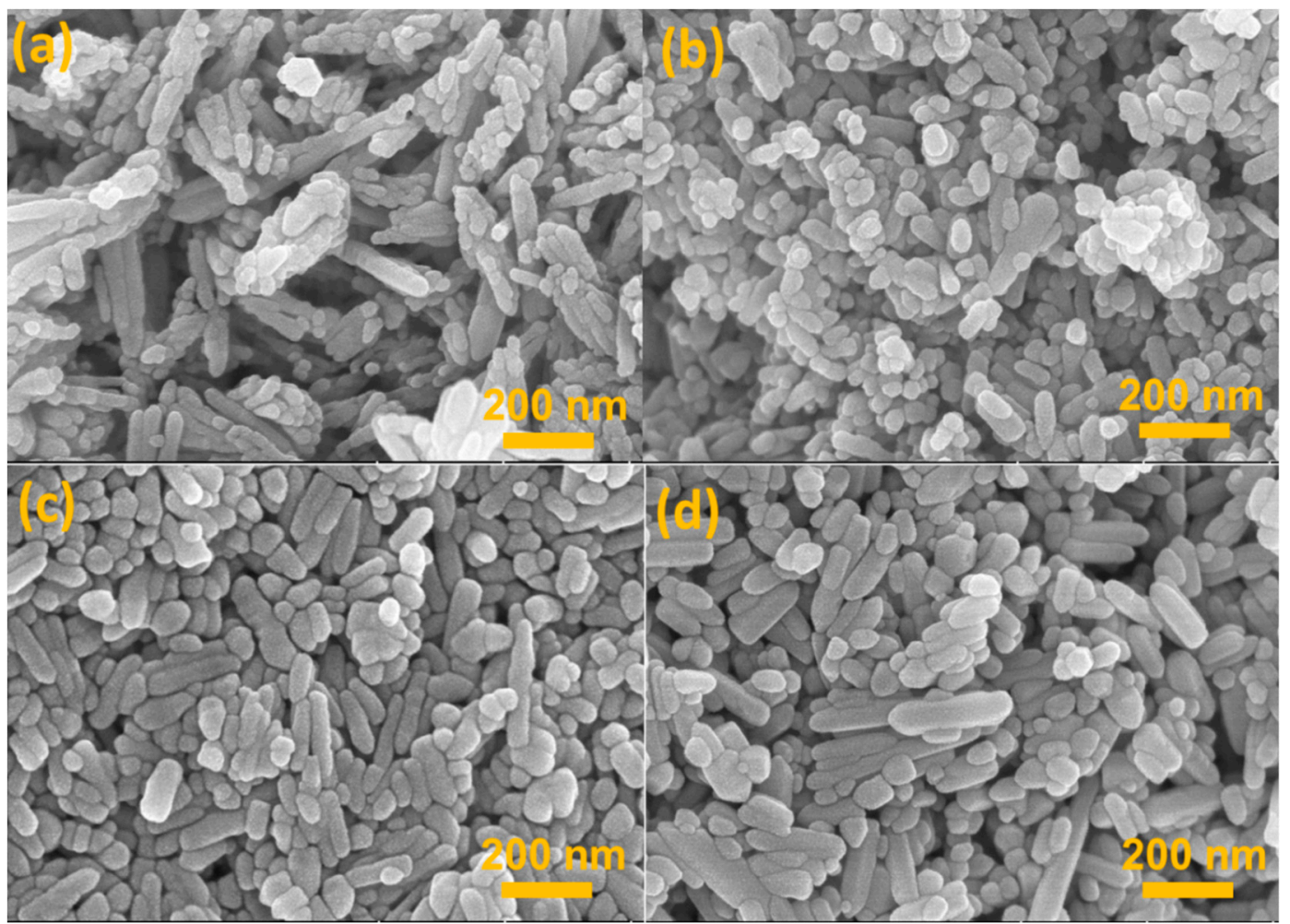

Figure 1. Scanning electron microscope (SEM) images of (a) Z1, (b) Z2, (c) Z3, and (d) Z4, respectively.
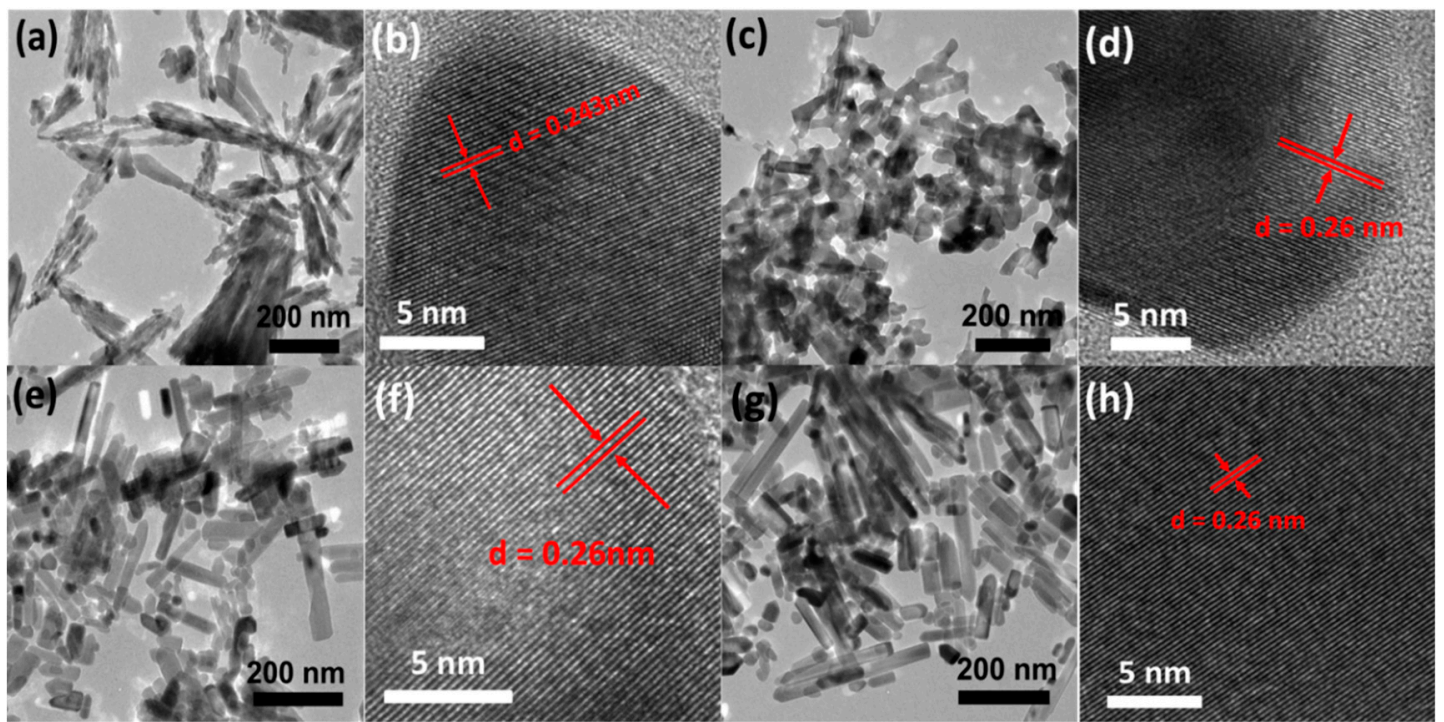

Figure 2. Transmission electron microscope (TEM) image and high-resolution (HRTEM) image of as-prepared ZnO samples: (a,b) Z1, (c,d) Z2, (e,f) Z3, and (g,h) Z4, respectively.

Table 1. Characteristics of various $\mathrm{ZnO}$ photoanodes together with the corresponding photovoltaic parameters.

\begin{tabular}{cccccccc}
\hline Sample & $\begin{array}{c}\text { Jsc } \\
\left(\mathbf{m A} / \mathbf{c m}^{2}\right)\end{array}$ & Voc (V) & FF & PCE & $\begin{array}{c}\text { Adsorbed Dye } \\
\left(\times \mathbf{1 0}^{-\mathbf{7}} \mathbf{m o l \cdot \mathbf { c m } ^ { - 2 } )}\right.\end{array}$ & $\begin{array}{c}\mathbf{S}_{\text {BET }} \\
\left(\mathbf{m}^{\mathbf{2}} \mathbf{g}\right)\end{array}$ & $\begin{array}{c}\text { Crystal } \\
\text { Size (nm) }\end{array}$ \\
\hline Z1 & 8.72 & 0.593 & 0.400 & 2.07 & 0.87 & 9.8 & 21.5 \\
Z2 & 13.30 & 0.591 & 0.405 & 3.18 & 1.35 & 15.4 & 19.8 \\
Z3 & 14.50 & 0.567 & 0.523 & 4.30 & 2.15 & 24.4 & 20.6 \\
Z4 & 10.28 & 0.545 & 0.556 & 3.12 & 1.41 & 16.6 & 22.8. \\
\hline
\end{tabular}


At elevated synthesis temperature of $160^{\circ} \mathrm{C}$, the acquired composite products presented NPs with minimum size of $15 \mathrm{~nm}$ and NRs with maximum length of $200 \mathrm{~nm}$ and uniform diameter (Figures 1c and S2). Comparison with Z2 revealed a significant decrease in interconnections between NPs in Z3 sample, similar to findings of Cao et al. which noticed a gradual reduction in the degree of aggregation in primary nanocrystallites at synthesis temperatures from $160^{\circ} \mathrm{C}$ to $190{ }^{\circ} \mathrm{C}$ [30]. Moreover, despite the improved dispersion of NPs and NRs in sample Z3, no obvious increase in particles size was observed. This may partially be ascribed to intrinsic nature of the employed solvent (diethylene glycol). As reported previously, the significant increase of $\mathrm{OH}^{-}$in the solution will definitely result in the formation of $\left[\mathrm{Zn}(\mathrm{OH})_{4}\right]^{2-}$, which is inclined to adsorb on the positively charged (0001) facet of the $\mathrm{ZnO}$, thus facilitating growth along the (0001) orientation [33]. However, the nonpolar nature of diethylene glycol medium inhibited the anisotropic growth of $\mathrm{ZnO}$ crystals to a large extent. At synthesis temperature of $180^{\circ} \mathrm{C}, \mathrm{ZnO}$ nanostructures still comprised of NPs and NRs but most $\mathrm{ZnO}$ surfaces became smoother and the tips sharper when compared to the product obtained at $160{ }^{\circ} \mathrm{C}$ (Figures $1 \mathrm{~d}$ and $2 \mathrm{~g}$ ), suggesting the noticeable impact of reaction temperature on the morphologic features. Moreover, the diameters of NRs looked almost uniform along the growth direction in spite of different lengths, and seemed larger than that of Z3, which could bring about a slight sacrifice of the overall surface area of $\mathrm{ZnO}$ products and thus dye absorption amount, as confirmed by characteristic parameters shown in Table 1. Both HRTEM images of Z3 and Z4 (Figure 2f,h) revealed lattice spacing constant around $0.26 \mathrm{~nm}$, indicating the fringes of (001) plane and suggesting preferred growth along the (0001) direction.

Compared to other reports dealing with diethylene glycol mediated synthesis route, the morphologies of our products appeared unique despite the use of same raw materials $[8,28,34]$. The reason for this would presumably be related to the absence of stirring during the entire synthesis process. This also induced major differences with respect to other similar studies at the exception of the reaction temperature. To confirm this assumption, $\mathrm{ZnO}$ specimens were also prepared by immersing the sealed stainless steel autoclave in a thermostatic oil bath at $160{ }^{\circ} \mathrm{C}$. As can be seen in Figure 3, the amount of spherical aggregates increased gradually as stirring speed changed from low to high, confirming the pivotal role played by stirring speed on the morphology of $\mathrm{ZnO}$ structure. The reason for this could be attributed to the concentration gradient of $\mathrm{Zn}$ ions in the solvent, which would significantly be influenced by stirring. This, in turn, affected the supersaturation levels and mass transport during the reaction to some extent, leading to variation in aggregating degree and composition unit $[26,35]$. 


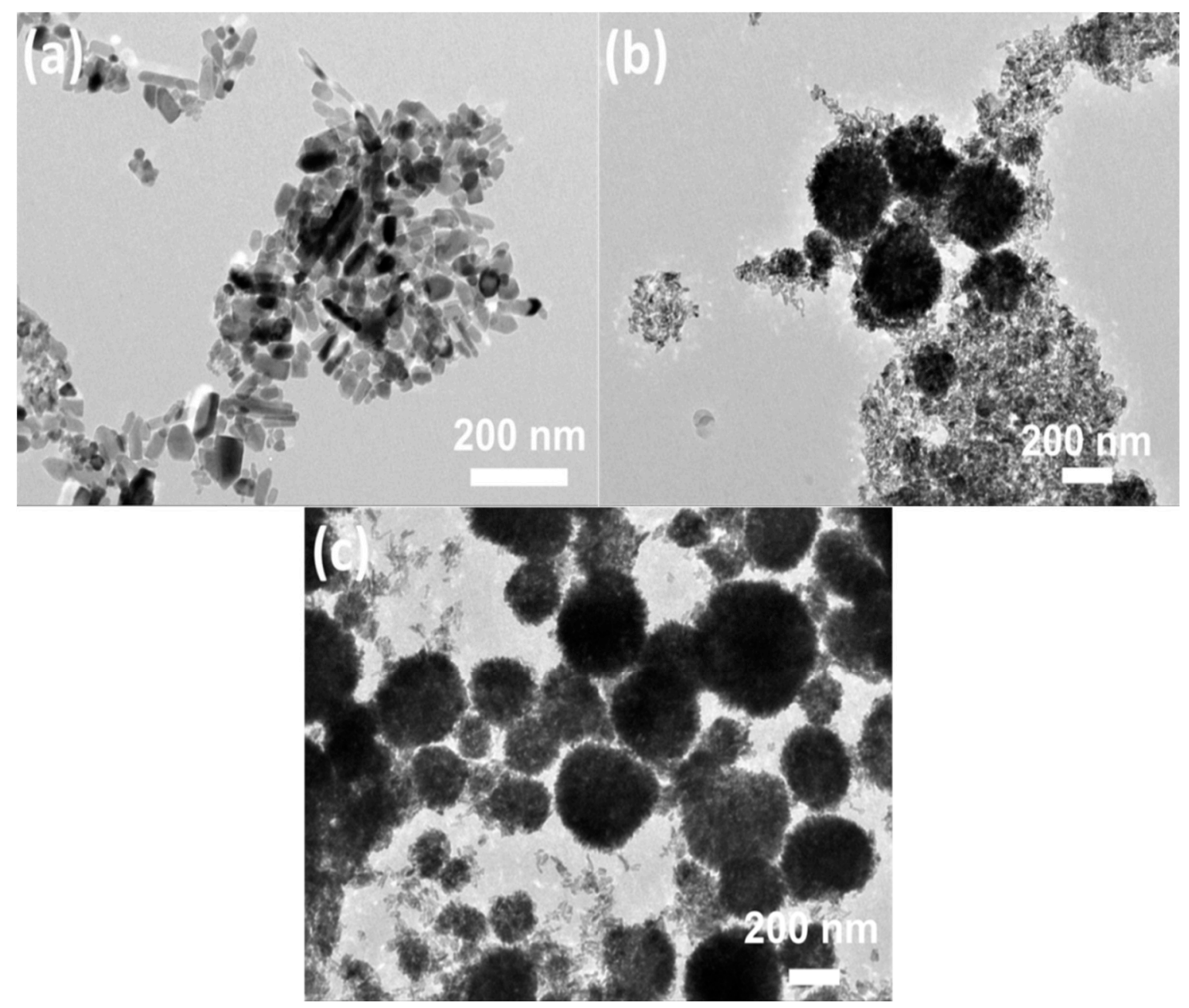

Figure 3. TEM images of $\mathrm{ZnO}$ synthesized via a thermostatic oil bath method at $160{ }^{\circ} \mathrm{C}$ under different stirring rate: (a) $0 \mathrm{r} / \mathrm{min}$, (b) $800 \mathrm{r} / \mathrm{min}$, and (c) $2000 \mathrm{r} / \mathrm{min}$.

\subsection{X-ray Diffraction (XRD) Analysis}

To confirm the crystal structures of the fabricated $\mathrm{ZnO}, \mathrm{X}$-ray diffraction (XRD) patterns were recorded and the results are depicted in Figure 4. The diffraction peaks of all specimens Z1-Z4 looked sharp, indicating high crystallinity. Moreover, it can be clearly observed that almost no obvious peak intensity variation is detected for all the products despite notable morphology differences, indicating the slight crystal size difference [36]. Therefore, though the reaction temperature significantly influenced the composition unit, its effect on crystallinity was almost negligible. Further observations revealed that all characteristic diffraction peaks could be well indexed to specific crystal planes of wurtzite hexagonal structured $\mathrm{ZnO}$ (JCPDS No. 36-1451). On the other hand, no diffraction peaks belonging to the secondary phase or impurities were detected, implying the high purity of the fabricated $\mathrm{ZnO}$ nanostructures [37]. By comparing with other peaks, it can be easily visualized that the full width of the (002) peak is relatively narrower, probably indicating that the growth along the (0001) direction is preferred for the as-formed $\mathrm{ZnO}$ crystal, [38] which is consistent with TEM image shown in Figure 2. 


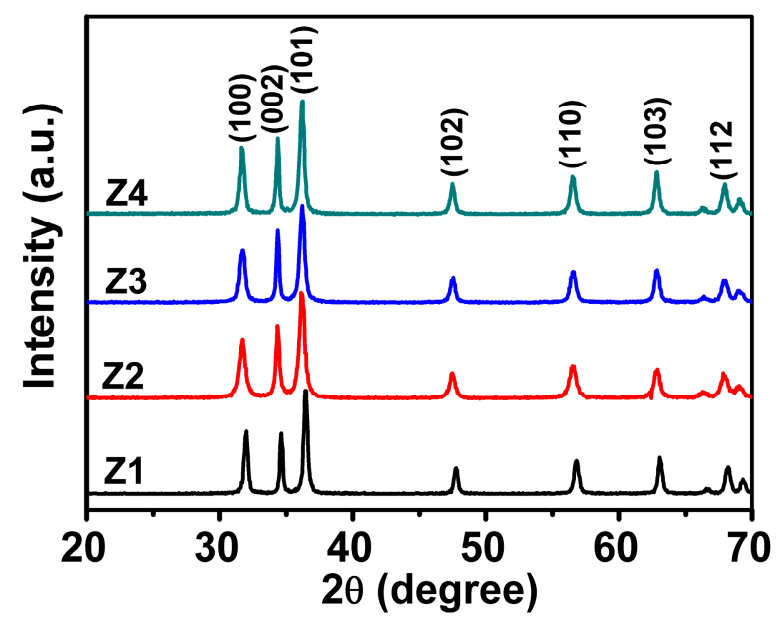

Figure 4. Typical X-ray diffraction (XRD) patterns of $\mathrm{ZnO}$ products from $\mathrm{Z1}$ to $\mathrm{Z} 4$.

\subsection{Photovoltaic Performance Test}

To evaluate the photovoltaic properties of the as-prepared $\mathrm{ZnO}$, four types of DSCs based on samples $\mathrm{Z1}-\mathrm{Z} 4$ were constructed, and current versus voltage $(\mathrm{J}-\mathrm{V})$ behaviors were tested under illumination of AM 1.5 simulated sunlight $\left(100 \mathrm{~mW} \cdot \mathrm{cm}^{-2}\right)$. Typical J-V curves and calculated functional parameters, including open-circuit voltage (Voc), short-circuit current density (Jsc), fill factor (FF), and PCE are gathered in Figure 5a and Table 1. As shown in Figure 5a, the obtained Jsc, Voc, and PCE varied among Z1 to Z4. Typically, Z1 with fan-shaped nanostructure achieved Jsc of $8.72 \mathrm{~mA} \cdot \mathrm{cm}^{-2}$, Voc of $0.593 \mathrm{~V}$, and PCE of $2.07 \%$. Note that conversion efficiencies ranging from $1.5 \%$ to $2.7 \%$ were generally achieved by DSCs based on NRs and NWs, indicating the inherent limitation of formed architecture [39-41]. The increase in temperature to $140{ }^{\circ} \mathrm{C}$ and $160{ }^{\circ} \mathrm{C}$ remarkably raised Jsc of Z2- and Z3-based DSCs to yield values reaching $13.30 \mathrm{~mA} \cdot \mathrm{cm}^{-2}$ and $14.50 \mathrm{~mA} \cdot \mathrm{cm}^{-2}$, respectively. By contrast, Voc of Z3 and Z4 showed reverse trends, with a decline in values to $0.591 \mathrm{~V}$ and $0.567 \mathrm{~V}$, respectively. Afterward, the current density showed an abrupt decrease to $10.28 \mathrm{~mA} \cdot \mathrm{cm}^{-2}$ as reaction temperature increased to $180^{\circ} \mathrm{C}$. Therefore, Z3 with maximum Jsc had the highest conversion efficiency $(4.30 \%)$ among all products under identical conditions. Such a relationship between the photovoltaic performance and reaction temperature further confirmed the difference in morphology and structure among Z1-Z4. For a given DSC system, the current density would most definitely be determined by the synergy of light harvesting and electron transport properties of the resultant film. Hence, the dye loading amount, optical properties and electron transport capabilities were systemically studied to clarify probable mechanisms underlying discrepancies in photovoltaic performances.

The dependence of Jsc and PCE on the thickness of Z3 was also systematically investigated to effectively combine the energy harvesting with electron transport of the photoanode configuration. As shown in Figure 5b, the current density first increased from 12.7 to $14.50 \mathrm{~mA} \cdot \mathrm{cm}^{-2}$ with film thickness from 9.8 to $14.7 \mu \mathrm{m}$ and then drastically decreased to $11.7 \mathrm{~mA} \cdot \mathrm{cm}^{-2}$ at film thickness of $20 \mu \mathrm{m}$. The PCE of corresponding specimens with different thicknesses were recorded as $3.74 \%, 4.30 \%$ and $3.44 \%$, respectively. No linear relationship between Jsc or PCE and thickness of ZnO photoanode was noticed, which might be ascribed to competing effects between the enhanced light harvesting arising from the increased dye adsorption and charge recombination within the resultant film, both believed to be closely related to photoanode thickness [9,42]. 

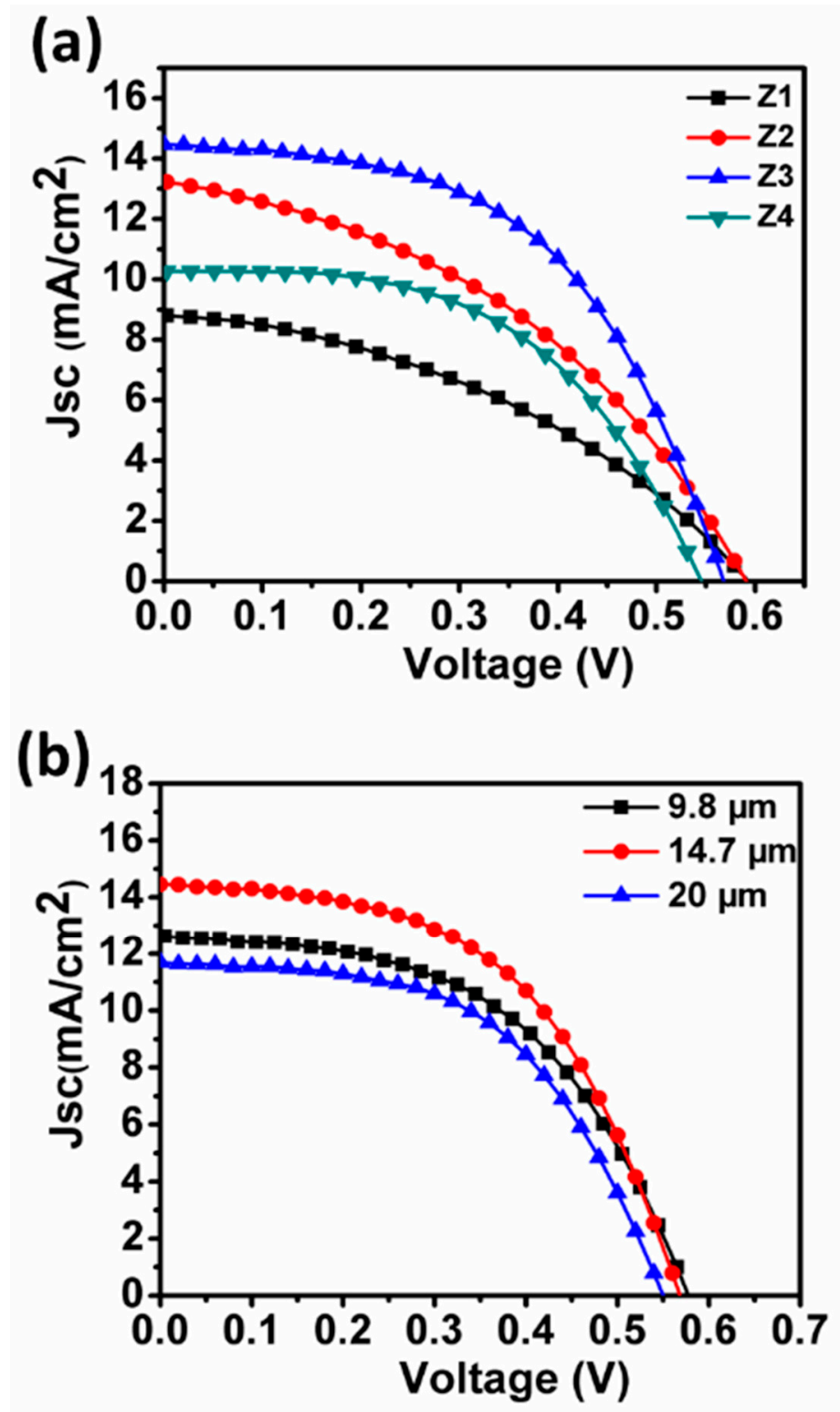

Figure 5. (a) J-V characteristic curves of various dye-sensitized solar cell (DSC) devices and (b) J-V characteristic curves of Z3-based solar cells as a function of film thickness.

\subsection{Dye Absorption and Diffuse Reflectivity}

To explore the origin of the obvious difference in photovoltaic performance between samples, the dye-loading capabilities of $\mathrm{ZnO}$ films with various structures were studied and the corresponding results are listed in Table 1 . The attached dye amounts of Z1, Z2 and Z3 were estimated to be $0.87 \times 10^{-7}$, $1.35 \times 10^{-7}$ and $2.15 \times 10^{-7} \mathrm{~mol} \cdot \mathrm{cm}^{-2}$, respectively. This confirmed the gradual increasing trend with temperature from 120 to $160{ }^{\circ} \mathrm{C}$. However, $\mathrm{Z} 4$ depicted an ultimate decrease in dye loading amount $\left(1.41 \times 10^{-7} \mathrm{~mol} \cdot \mathrm{cm}^{-2}\right)$. Since all photoanode films had the same thickness, the significant discrepancy in dye absorption must be due to the difference in overall surface area between samples. The latter was confirmed by BET specific surface area $\left(\mathrm{S}_{\mathrm{BET}}\right)$ measurements provided in Table 1 . $\mathrm{Z} 3$ presented the highest surface area of $24.4 \mathrm{~m}^{2} \cdot \mathrm{g}^{-1}$, whereas $\mathrm{Z1}$ revealed the lowest value of $9.8 \mathrm{~m}^{2} \cdot \mathrm{g}^{-1}$ followed by $\mathrm{Z} 2$ and $\mathrm{Z4}$, displaying the same variation trend as the amount of absorbed dye. Higher dye loading amount makes it possible for sufficient absorption of incident photons, thus providing the possibility of achieving larger Jsc and PCE. 
To estimate the light-scattering properties of resultant $\mathrm{ZnO}$ photoanode films, the diffuse reflectance spectra were further investigated and the data are provided in Figure 6. The reflectance values of Z1 and Z2 films were apparently higher than those of Z3 and Z4 over the wavelength range of 450-800 nm. Hence, films constructed with fan-shaped NRs and partially aggregated NRs and NPs had higher reflecting abilities than the other two films assembled with relatively dispersed NRs and NPs. This was understandable since aggregation or assembling of NRs and/or NPs did not only favor the formation of large particles with size comparable to the wavelength of incident light but also benefited formation of voids, resulting in enhanced light scattering and decreased light transmittance of the incident light. In addition, the reflectivity difference between $\mathrm{Z} 1$ and $\mathrm{Z} 2$ might also be associated with the degree of aggregation or arranging pattern of the fundamental composition units (NRs and NPs). By comparison, the distinction between $\mathrm{Z} 3$ and $\mathrm{Z} 4$ could mainly be attributed to the partial retention of tight connection between NRs and NPs in Z3 (Figure 2). Higher light-scattering capacities would mean more trapped and utilized light, resulting in improved electron generation within the photoanode film and enhanced Jsc. However, since Z3 presented considerably lower light scattering ability, its highest Jsc value for Z3 is most likely attributed to the increased light harvesting arising from the larger surface area-induced efficient dye absorption rather than light reflecting and scattering within the film.

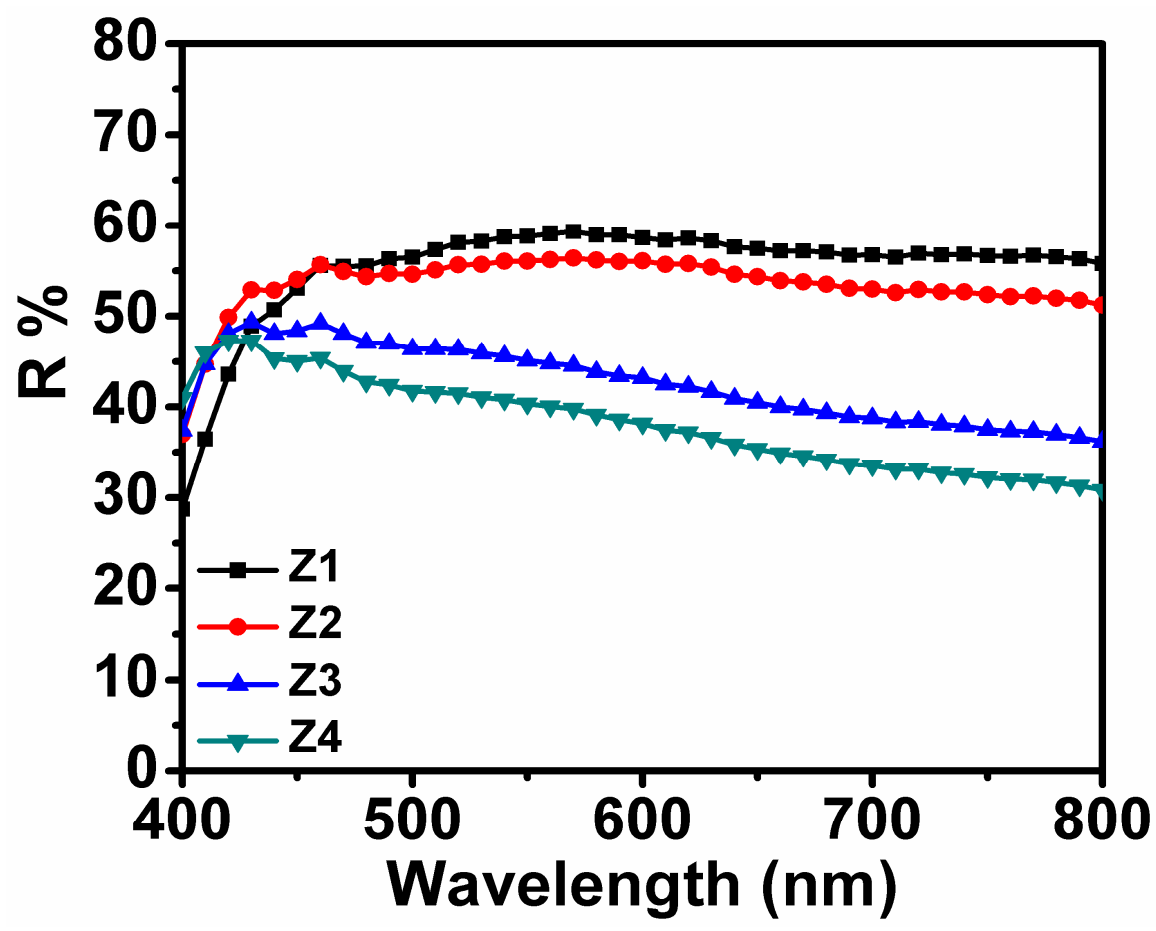

Figure 6. Diffuse reflectance spectra of all four photoanode films from Z1 to Z4.

\subsection{Electrochemical Impedance Spectroscopy (EIS) Analysis}

To gain a deeper understanding of charge transfer behaviors of $\mathrm{ZnO}$ DSCs, electrochemical impedance spectroscopy (EIS) was performed at applied bias of Voc in the dark. In Figure 7a, two distinguishable semicircles were clearly observed in the EIS Nyquist plot. The first was related to redox reactions at the $\mathrm{Pt} / \mathrm{electrolyte}$ interface while the second was associated with charge transfer processes occurred at oxide semiconductor film/dye/electrolyte interface. In general, information related to the electron transport properties of semiconductor films can be obtained directly from the Nyquist plot $[13,43,44]$. In particular, the extent of charge recombination could visually be judged from the diameter of the second central arc at medium frequencies. The central arc diameter in Nyquist plots decreased in the following sequence: $Z 1>Z 2>Z 3>Z 4$, implying the gradually decreased recombination resistance from Z1 to Z4. Compared to Z3 and Z4, the special 1-D structure in Z1 and effective connectivity between NPs and NRs in Z2 could effectively reduce the electron trapping sites 
(defects, grain boundaries, and surface states) in the photoanode films to facilitate the electron transport. The elevated resistance of Z3 could be explained by morphology. Even though Z3 presented smaller sized NPs and shorter length NRs when compared to Z4, the existence of partially interconnected NPs and NRs may play a key role in decreasing possible charge recombination. The electrons' lifetime $\left(\tau_{e}\right)$ values in various $\mathrm{ZnO}$ films were estimated according to the formula: $\tau_{e}=1 / \omega_{\max }=1 / 2 \pi f_{\max }$, where $f_{\text {max }}$ is the maximum frequency of mid-frequency peaks in Bode phase plots (Figure $7 \mathrm{~b}$ ). The $\tau_{\mathrm{e}}$ values were recorded as $6.2 \mathrm{~ms}$ for Z1, $5.3 \mathrm{~ms}$ for Z2, $4.7 \mathrm{~ms}$ for Z3, and $4.1 \mathrm{~ms}$ for Z4. The latter further demonstrated the dependence of electron transport on morphology characteristics. The much longer electron lifetimes signifies a faster diffusion rate of electrons in the films, matching the improved overall efficiencies.
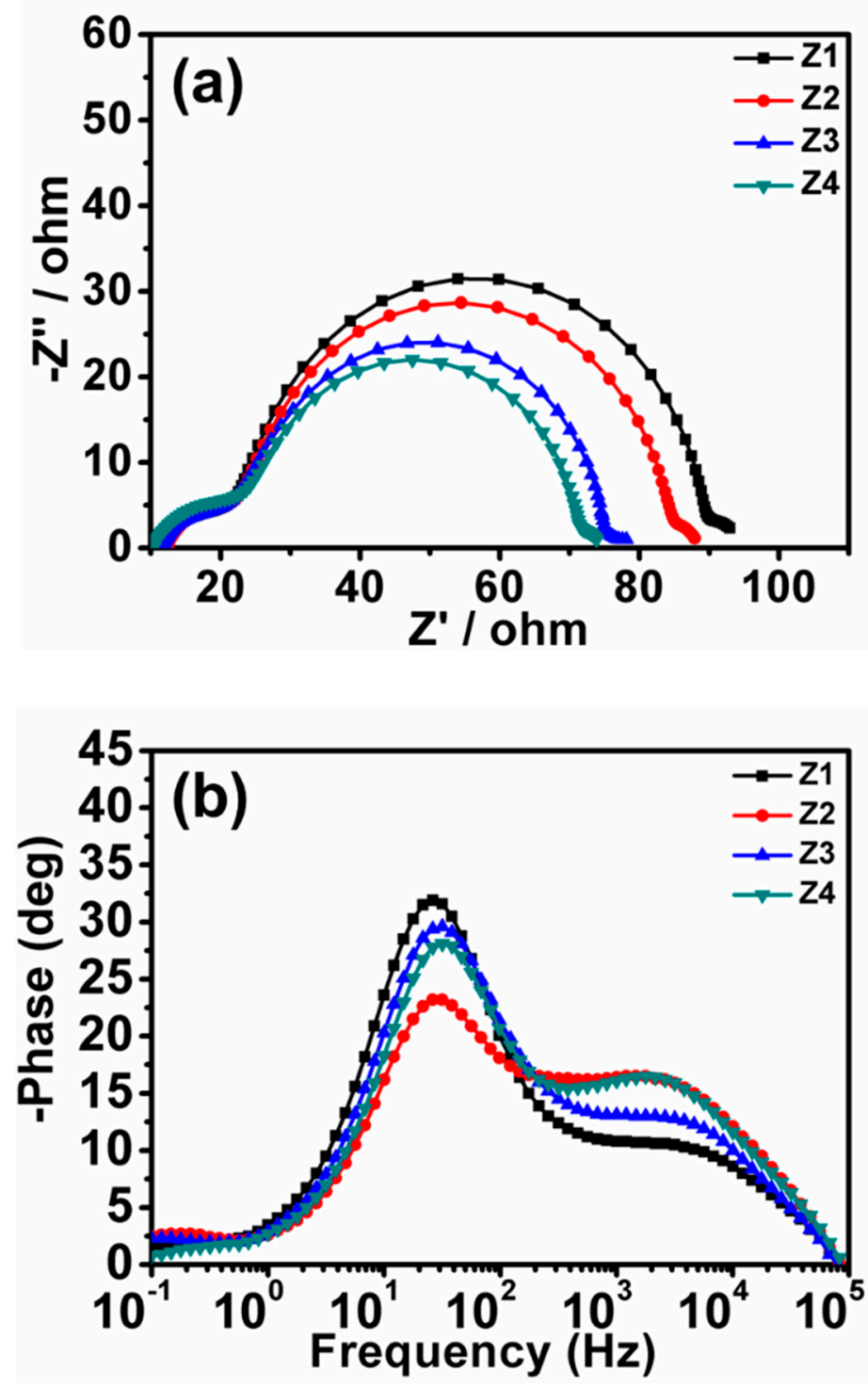

Figure 7. (a) Nyquist plots and (b) Bode phase plots of the $\mathrm{ZnO}$ cells.

\subsection{Incident Photon-to-Current Conversion Efficiency (IPCE) Measurements}

Figure 8 compares the IPCE values of cells constructed with various samples. Clearly, Z3 based cell provided the highest IPCE value among all devices, followed by Z2, Z4 and Z1, consistent with the trend of JSc (Figure 5). IPCE would be related predominantly to the efficiencies of sunlight harvesting, as well as electron injection and collection. Since the same sensitizer (N719) and iodine-based electrolyte were applied to all $\mathrm{ZnO}$ based cells, the change in IPCE can be attributed mainly to variation in light 
harvesting efficiency and/or charge collection efficiency $[8,9,13]$. These features would originate from dye absorption and light scattering capabilities, as well as electron transport properties. As revealed by the UV-vis absorption and EIS spectra, Z3 showed higher dye attachment, enhanced light harvesting, and improved electron transport properties when compared to Z4. Therefore, much higher IPCE of $Z 3$ with respect to $Z 4$ could be ascribed to the synergic effects of the aforementioned favoring factors. For Z1 and Z2, the decreased IPCE values could be ascribed to the reduced dye absorption abilities of the resultant photoanode films despite their higher light-scattering capabilities and larger recombination resistances.

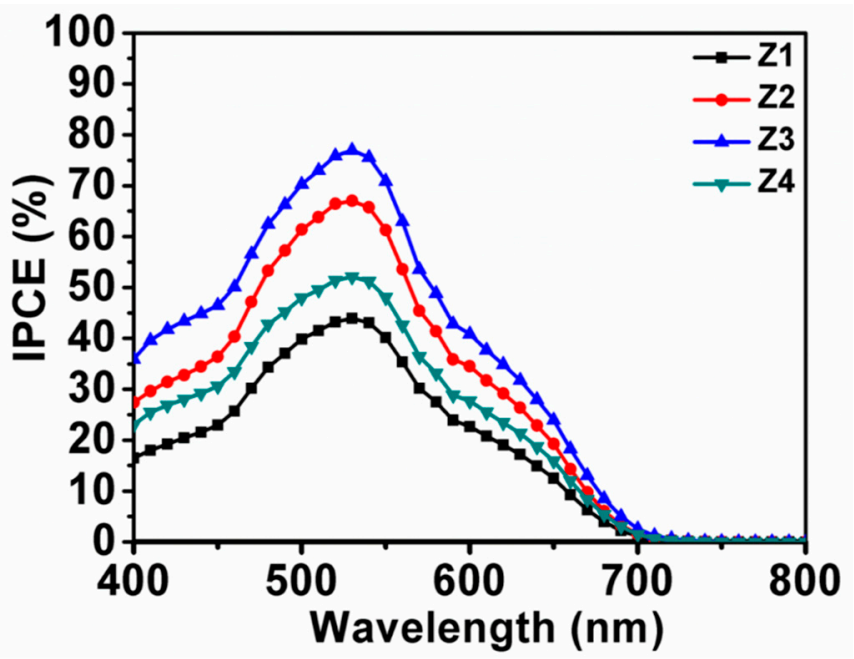

Figure 8. Incident photon-to-current conversion efficiency (IPCE) spectra of devices with the photoanode films constructed with Z1 to Z4.

\section{Conclusions}

In summary, a facile one-pot solvothermal method was successfully developed for the synthesis of a class of novel $\mathrm{ZnO}$ architectures composed of 1-D NRs and 0-D NPs. Fine tuning morphology and structure of $\mathrm{ZnO}$ were realized by controlling the experimental parameters, such as reaction temperature and stirring rate. This made it feasible to optimize the photovoltaic performances by maximizing the required characteristics (large dye-loading amount, excellent light scattering, and fast electron transport) of the photoelectrode. As a consequence, a significantly improved PCE of $4.30 \%$ was achieved for the sample synthesized at $160^{\circ} \mathrm{C}$ (i.e., Z3) under an optimized film thickness of $14.7 \mu \mathrm{m}$. The material and device characterizations revealed that $0-\mathrm{D} \mathrm{ZnO}$ NPs played a pivotal role in improving the specific surface area for abundant dye absorption, while locally tight interconnection between 1-D NRs and 0-D NPs were favorable for fast electron transport and excellent light scattering. Overall, the proposed approach offered a feasible way for outstanding cell efficiencies by directional control of $\mathrm{ZnO}$ architecture, which should be applicable for the design of other photoanode materials of DSCs.

Supplementary Materials: The following are available online at http://www.mdpi.com/2079-4991/9/7/931/s1, Figure S1: The TEM image of (a) magnified fan-shaped bundles, (b) aggregated NRs, and (b) aggregated NPs in Z1 recorded from Talos F200 X. Figure S2: Magnified TEM image of Z3, Figure S3: The error bars of the key photovoltaic parameters.

Author Contributions: D.W. designed the experiments; Y.Z., M.S., T.X. and H.Y. carried out the experiments; S.B., analyzed the data; D.W. wrote the paper; X.Z., Y.F. and J.Z. review and edited the paper.

Funding: This work was supported by Shandong Province Natural Science Foundation of China (ZR2018LB032) and National Natural Science Foundation of China (51473074, 31400044).

Conflicts of Interest: The authors declare no conflicts of interest. 


\section{References}

1. Freitag, M.; Teuscher, J.; Saygili, Y.; Zhang, X.Y.; Giordano, F.; Liska, P.; Hua, J.L.; Zakeeruddin, S.M.; Moser, J.E.; Grätzel, M.; et al. Dye-Sensitized Solar Cells for Efficient Power Generation under Ambient Lighting. Nat. Photonics 2017, 11, 372. [CrossRef]

2. Wu, G.H.; Kong, F.T.; Zhang, Y.H.; Zhang, X.X.; Li, J.Z.; Chen, W.C.; Liu, W.Q.; Ding, Y.; Zhang, C.N.; Zhang, B.; et al. Multiple-Anchoring Triphenylamine Dyes for Dye-Sensitized Solar Cell Application. J. Phys. Chem. C 2014, 118, 8756-8765. [CrossRef]

3. Wang, D.T.; Liu, S.H.; Shao, M.F.; Zhao, J.H.; Gu, Y.K.; Li, Q.Y.; Zhang, X.X.; Zhao, J.S.; Fang, Y.Z. Design of $\mathrm{SnO}_{2}$ Aggregate/Nanosheet Composite Structures Based on Function-Matching Strategy for Enhanced Dye-Sensitized Solar Cell Performance. Materials 2018, 11, 1774. [CrossRef] [PubMed]

4. Zhou, H.W.; Yin, J.; Nie, Z.H.; Yang, Z.J.; Wang, J.H.; Liu, X.; Jin, C.Z.; Zhang, X.X.; Ma, T.L. Earth-Abundant and Nano-Micro Composite Catalysts of $\mathrm{Fe}_{3} \mathrm{O}_{4} @$ reduced Graphene Oxide for Green and Economical Mesoscopic Photovoltaic Devices with High Effciencies up to 9\%. J. Mater. Chem. A 2016, 4, 67-73. [CrossRef]

5. Yin, J.; Zhou, H.W.; Liu, Z.C.; Nie, Z.H.; Li, Y.H.; Qi, X.; Chen. B., L.; Zhang, Y.T.; Zhang, X.X. Indium- and Platinum-Free Counter Electrode for Green Mesoscopic Photovoltaics through Graphene Electrode and Graphene Composite Catalysts: Interfacial Compatibility. ACS Appl. Mater. Interfaces 2016, 8, 5314-5319. [CrossRef] [PubMed]

6. Grätzel, M. Photoelectrochemical Cells. Nature 2001, 414, 338. [CrossRef] [PubMed]

7. Mathew, S.; Yella, A.; Gao, P.; Humphry-Baker, B.; Curchod, B.F.E.; Ashari-Astani, N.; Tavernelli, I.; Rothlisberger, U.; Nazeeruddin, M.K.; Grätzel, M. Dye-Sensitized Solar Cells with 13\% Efficiency Achieved through the Molecular Engineering of Porphyrin Sensitizers. Nat. Chem. 2014, 6, 242. [CrossRef]

8. Wang, D.T.; Wang, W.X.; Ma, X.Y.; Zhang, C.; Zhao, J.S.; Zhang, X.X. Comparative Study on the Influence of $\mathrm{TiO}_{2}$ Precursors on ZnO-Based Dye-Sensitized Solar Cells. Ind. Eng. Chem. Res. 2015, 54, 12639-12645. [CrossRef]

9. Wang, D.T.; Liu, S.H.; Shao, M.F.; Li, Q.Y.; Gu, Y.K.; Zhao, J.H.; Zhang, X.X.; Zhao, J.S.; Fang, Y.Z. Aqueous Solution-Processed Multifunctional $\mathrm{SnO}_{2}$ Aggregates for Highly Efficient Dye-Sensitized Solar Cells. Ind. Eng. Chem. Res. 2018, 57, 7136-7145. [CrossRef]

10. Chen, J.J.; Lu, L.Y.; Wang, W.Y. $\mathrm{Zn}_{2} \mathrm{SnO}_{4}$ Nanowires as Photoanode for Dye-Sensitized Solar Cells and the Improvement on Open-Circuit Voltage. J. Phys. Chem. C 2012, 116, 10841-10847. [CrossRef]

11. Chu, L.; Liu, W.; Yu, A.A.; Qin, Z.F.; Hu, R.Y.; Shu, H.Z.; Luo, Q.P.; Min, Y.G.; Yang, J.P.; Li, X.A. Effect of TiO 2 Modification on Urchin-like Orthorhombic $\mathrm{Nb}_{2} \mathrm{O}_{5}$ Nanospheres as Photoelectrodes in Dye-Sensitized Solar Cells. Sol. Energy 2017, 153, 584-589. [CrossRef]

12. Lu, X.H.; Zheng, Y.Z.; Bi, S.Q.; Wang, Y.; Tao, X.; Dai, L.M.; Chen, J.F. Multidimensional ZnO Architecture for Dye-Sensitized Solar Cells with High-Efficiency up to 7.35\%. Adv. Energy Mater. 2014, 4, 1301802. [CrossRef]

13. Zhai, Y.L.; Zhai, S.Y.; Chen, G.F.; Zhang, K.; Yue, Q.L.; Wang, L.; Jia, J.B. Effects of Morphology of Nanostructured ZnO on Direct Electrochemistry and Biosensing Properties of Glucose Oxidase. J. Electroanal. Chem. 2011, 656, 198-205. [CrossRef]

14. Wang, L.; Yue, Q.L.; Li, H.B.; Xu, S.L.; Liu, J.F. Study on Electrochemiluminescence Spectra of ZnO Flakes. Phys. Chem. Chem. Phys. 2013, 15, 9058-9061. [CrossRef] [PubMed]

15. Wu, D.P.; Gao, Z.Y.; Xu, F.; Chang, J.L.; Tao, W.G.; He, J.J.; Gao, S.Y.; Jiang, K. Hierarchical ZnO Aggregates Assembled by Orderly Aligned Nanorods for Dye-Sensitized Solar Cells. CrystEngComm 2013, 15, 1210-1217. [CrossRef]

16. Memarian, N.; Concina, I.; Braga, A.; Rozati, S.M.; Vomiero, A.; Sberveglieri, G. Hierarchically Assembled ZnO Nanocrystallites for High-Efficiency Dye-Sensitized Solar Cells. Angew. Chem. Int. Ed. 2011, 123, 12321-12325. [CrossRef] [PubMed]

17. Zhu, K.; Neale, N.R.; Miedaner, A.; Frank, A.J. Enhanced Charge-Collection Efficiencies and Light Scattering in Dye-Sensitized Solar Cells Using Oriented $\mathrm{TiO}_{2}$ Nanotubes Arrays. Nano Lett. 2007, 7, 69-74. [CrossRef]

18. Sang, D.D.; Li, H.D.; Wang, Q.L. Aligned ZnO Nanorod Arrays Growth on GaN QDs for Excellent Optoelectronic Applications. Nanotechnology 2016, 27, 072501. [CrossRef]

19. Periasamy, A.P.; Liu, J.F.; Lin, H.M.; Chang, H.T. Synthesis of Copper Nanowire Decorated Reduced Graphene Oxide for Electro-Oxidation of Methanol. J. Mater. Chem. A 2013, 1, 5973-5981. [CrossRef] 
20. Galoppini, E.; Rochford, J.; Chen, H.H.; Saraf, G.; Lu, Y.C.; Hagfeldt, A.; Boschloo, G. Fast Electron Transport in Metal Organic Vapor Deposition Grown Dye-Sensitized ZnO Nanorod Solar Cells. J. Phys. Chem. B 2006, 110, 16159-16161. [CrossRef]

21. Karam, C.; Habchi, R.; Tingry, S.; Miele, P.; Bechelany, M. Design of Multilayers of Urchin-Like ZnO Nanowires Coated with $\mathrm{TiO}_{2}$ Nanostructures for Dye-Sensitized Solar Cells. ACS Appl. Nano Mater. 2018, 1, 3705-3714. [CrossRef]

22. Karam, C.; Guerra-Nuñez, C.; Habchi, R.; Herro, Z.; Abboud, N.; Khoury, A.; Tingry, S.; Miele, P.; Utke, I.; Bechelany, M. Urchin-Inspired $\mathrm{ZnO}-\mathrm{TiO}_{2}$ Core-Shell as Building Blocks for Dye sensitized Solar Cells. Mater. Des. 2017, 126, 314-321. [CrossRef]

23. Zheng, Y.Z.; Ding, H.Y.; Liu, Y.; Tao, X.; Cao, G.Z.; Chen, J.F. In Situ Hydrothermal Growth of Hierarchical ZnO Nanourchin for High-Efficiency Dye-Sensitized Solar Cells. J. Power Sources 2014, 254, 153-160. [CrossRef]

24. Roy, A.; Mukhop, S. Polyaniline-Layered Rutile $\mathrm{TiO}_{2}$ Nanorods as Alternative Photoanode in Dye-Sensitized Solar Cells. ACS Omega 2019, 4, 1130-1138. [CrossRef]

25. Kim, H.J.; Yong, K. A Highly Efficient Light Capturing 2D (Nanosheet)-1D (Nanorod) Combined Hierarchical ZnO Nanostructure for Efficient Quantum Dot Sensitized Solar Cells. Phys. Chem. Chem. Phys. 2013, 15, 2109-2116. [CrossRef]

26. Gao, R.; Cui, Y.X.; Liu, X.J.; Wang, L.D.; Cao, G.Z. A ZnO Nanorod/Nanoparticle Hierarchical Structure Synthesized through a Facile In Situ Method for Dye-Sensitized Solar Cells. J. Mater. Chem. A 2014, 2, 4765-4770. [CrossRef]

27. Guillén, E.; Azaceta, E.; Vega-Poot, A.; Idígoras, J.; Echeberría, J.; Anta, J.A.; Tena-Zaera, R. ZnO/ZnO Core-Shell Nanowire Array Electrodes: Blocking of Recombination and Impressive Enhancement of Photovoltage in Dye-Sensitized Solar Cells. J. Phys. Chem. C 2013, 117, 13365-13373. [CrossRef]

28. Chen, L.Y.; Yin, Y.T. Hierarchically Assembled ZnO Nanoparticles on High Diffusion Coefficient ZnO Nanowire Arrays for High Efficiency Dye-Sensitized Solar Cells. Nanoscale 2013, 5, 1777-1780. [CrossRef]

29. Yodyingyong, S.; Zhang, Q.F.; Park, K.; Dandeneau, C.S.; Zhou, X.Y.; Triampo, D.; Cao, G.G. ZnO Nanoparticles and Nanowire Array Hybrid Photoanodes for Dye-Sensitized Solar Cells. Appl. Phys. Lett. 2010, 96, 073115. [CrossRef]

30. Zhang, Q.F.; Chou, T.P.; Russo, B.; Jenekhe, S.A.; Cao, G.Z. Aggregation of ZnO Nanocrystallites for High Conversion Efficiency in Dye-Sensitized Solar Cells. Angew. Chem. Int. Ed. 2008, 120, 2402-2406. [CrossRef]

31. Wang, X.J.; Zhang, Q.L.; Wan, Q.; Dai, G.Z.; Zhou, C.J.; Zou, B.S. Controllable ZnO Architectures by Ethanolamine-Assisted Hydrothermal Reaction for Enhanced Photocatalytic Activity. J. Phys. Chem. C 2011, 115, 2769-2775. [CrossRef]

32. Zhang, Q.F.; Chou, T.P.; Russo, B.; Jenekhe, S.A.; Cao, G.Z. Polydisperse Aggregates of ZnO Nanocrystallites: A Method for Energy-Conversion-Efficiency Enhancement in Dye-Sensitized Solar Cells. Adv. Funct. Mater. 2008, 18, 1654-1660. [CrossRef]

33. Weintraub, B.; Zhou, Z.Z.; Li, Y.H.; Deng, Y.L. Solution Synthesis of One-Dimensional ZnO Nanomaterials and Their Applications. Nanoscale 2010, 2, 1573-1587. [CrossRef] [PubMed]

34. Wang, L.; Li, R.; Feng, L.; Liu, J.F.; Gao, X.X.; Wang, W.J. Study on the Interface Electronic States of Chemically Modified ZnO Nanowires. RSC Adv. 2015, 5, 98130-98135. [CrossRef]

35. Pu, X.P.; Zhang, D.F.; Jia, L.P.; Su, C.H. Synthesis of Zinc Oxide Nanostructures with Controlled Morphologies Using a Simple Sonochemical Method. J. Am. Ceram. Soc. 2007, 90, 4076-4078. [CrossRef]

36. Elias, J.; Utke, I.; Yoon, S.; Bechelany, M.; Weidenkaff, A.; Michler, J.; Philippe, L. Electrochemical Growth of ZnO Nanowires on Atomic Layer Deposition Coated Polystyrene Sphere Templates. Electrochim. Acta 2013, 110, 387-392. [CrossRef]

37. Maiti, U.N.; Maiti, S.; Chattopadhyay, K.K. An Ambient Condition, One Pot Route for Large Scale Production of Ultrafine ( $<15 \mathrm{~nm}$ ) ZnO Nanowires from Commercial Zinc Exhibiting Excellent Recyclable Catalytic Performance: Approach Extendable to CuO Nanostructures. CrystEngComm 2012, 14, 640-647. [CrossRef]

38. Cahen, D.; Hodes, G.; Grätzel, M.; Guillemoles, J.F.; Riess, I. Nature of Photovoltaic Action in Dye-Sensitized Solar Cells. J. Phys. Chem. B 2000, 104, 2053-2059. [CrossRef]

39. Guo, D.P.; Xiao, S.Q.; Fan, K.; Yu, J.G. Hierarchical $\mathrm{TiO}_{2}$ Submicrorods Improve the Photovoltaic Performance of Dye-Sensitized Solar Cells. ACS Sustain. Chem. Eng. 2017, 5, 1315-1321. [CrossRef]

40. Qiu, J.H.; Guo, M.; Wang, X.D. Electrodeposition of Hierarchical ZnO Nanorod-Nanosheet Structures and Their Applications in Dye-Sensitized Solar Cells. ACS Appl. Mater. Interfaces 2011, 3, 2358-2367. [CrossRef] 
41. Yang, L.J.; Leung, W.W.F. Application of a Bilayer $\mathrm{TiO}_{2}$ Nanofiber Photoanode for Optimization of Dye-Sensitized Solar Cells. Adv. Mater. 2011, 23, 4559-4562. [CrossRef] [PubMed]

42. Adachi, M.; Sakamoto, M.; Jiu, J.; Ogata, Y.; Isoda, S. Determination of Parameters of Electron Transport in Dye-Sensitized Solar Cells Using Electrochemical Impedance Spectroscopy. J. Phys. Chem. B 2006, 110, 13872-13880. [CrossRef] [PubMed]

43. Lu, X.H.; Zheng, Y.Z.; Zhao, J.X.; Chen, J.F.; Tao, X. Aqueous Chemical Synthesis of Large-Scale ZnO Aggregates with High-Efficient Light-Scattering and Application in Dye-Sensitized Solar Cells. Electrochim. Acta 2013, 90, 649-655. [CrossRef]

44. Gao, C.; Peng, Y.Q.; Hu, L.H.; Mo, L.; Zhang, X.X.; Hayat, T.; Alsaedid, A.; Dai, S.Y. A Comparative Study of the Density of Surface States in Solid and Hollow $\mathrm{TiO}_{2}$ Microspheres. Inorg. Chem. Front. 2018, 5, 2284-2290. [CrossRef]

(C) 2019 by the authors. Licensee MDPI, Basel, Switzerland. This article is an open access article distributed under the terms and conditions of the Creative Commons Attribution (CC BY) license (http://creativecommons.org/licenses/by/4.0/). 